\title{
Optical coherence tomography findings of bilateral foveal leukemic infiltration
}

This article was published in the following Dove Press journal:

International Medical Case Reports Journal

8 August 2016

Number of times this article has been viewed

John Q Le'

Puneet S Braich ${ }^{2}$

Vikram S Brar ${ }^{2}$

'Department of Internal Medicine, ${ }^{2}$ Department of Ophthalmology,

Virginia Commonwealth University,

Richmond, VA, USA
Correspondence: Vikram S Brar Department of Ophthalmology, Virginia Commonwealth University, 40I N II th St, Suite 439, Richmond, VA 23298, USA

$\mathrm{Tel}+\mathrm{I} 8048289315$

Fax + I 8048281010

Email vbrar@mcvh-vcu.edu
Abstract: We report a case of a 59-year-old man with a history of atypical chronic myelogenous leukemia who presented with a several-week history of decreased vision in both eyes. His clinical examination revealed bilateral foveal infiltration, which was also demonstrated on optical coherence tomography. After a failed induction with imatinib $\left(\mathrm{Gleevec}^{\circledR}\right)$, he was treated with omacetaxine $\left(\right.$ Synribo $\left.^{\circledR}\right)$ with an appropriate hematologic response. As his leukemia improved with chemotherapy, his retinal lesions regressed as demonstrated by serial optical coherence tomography and fundus photographs, with near complete restoration of foveal architecture.

Keywords: leukemia, leukemic retinopathy, leukemic infiltration, OCT

\section{Introduction}

Leukemic retinopathy refers to numerous, abnormal fundoscopic findings that stem from complications of leukemia, such as anemia, thrombocytopenia, and hyperviscosity. ${ }^{1,2}$ The most prevalent of such findings include intraretinal hemorrhages, cotton-wool spots, and white-centered hemorrhages. These hemorrhages are typically found in the posterior pole and particularly in the inner layers with focal destruction. ${ }^{1}$ While ocular involvement can range from $39 \%$ to $53 \%$ of cases in patients with acute leukemia, ${ }^{1}$ only a small portion of these findings are a result of direct leukemic infiltration. In this case report, we present a rare scenario of bilateral, foveal leukemic infiltration, and vision loss in a patient with atypical chronic myelogenous leukemia who eventually had regression of these foveal lesions and recovered vision after chemotherapy. The clinical response was documented on serial spectral domain optical coherence tomography (OCT) imaging, with image registration.

\section{Case report}

A 59-year-old man with a history of asthma, hypertension, and newly diagnosed atypical chronic myelogenous leukemia, which was BCR-ABL receptor-negative, presented to the eye clinic with a several-week history of decreased vision, floaters and photopsia, and central scotomas. His best corrected visual acuity was 20/80 oculus uterque (OU), and intraocular pressures were 13 and $14 \mathrm{mmHg}$, respectively. His pupils were symmetric and reacted briskly to light without a relative afferent pupillary defect. His external slit-lamp examination was remarkable only for nuclear sclerosis OU. His dilated fundus exam revealed a posterior vitreous detachment in his right eye without vitreous hemorrhage. His cup-to-disk ratio was 0.85 with healthy rims and bilateral peripapillary

submit your manuscript | www.dovepress.con 
atrophy. Scattered white-centered hemorrhages were present throughout the fundus. Focal areas of leukemic infiltration were present in the fovea OU (Figure 1) with larger leukemic lesions temporally in right eye and inferotemporally in the left eye. OCT scans of the macula revealed hyperreflective lesions in the inner retina as well as a separate outer retinal lesion in the right eye (Figure 2). The left eye demonstrated a larger inner retinal lesion with smaller adjacent lesions, without an outer retinal component. There was no evidence of choroidal involvement or subretinal fluid.

The patient was diagnosed with chronic phase chronic myelogenous leukemia (BCR-ABL-negative) by bone marrow aspiration and biopsy with an overall cellularity of $95 \%$. The myeloid series was increased and left shifted with full maturation. Flow cytometry with CD34 staining showed $<5 \%$ blasts. Cytogenetic studies showed 47, XXY. Unlike acute lymphoblastic leukemia, central nervous system involvement in chronic myelogenous leukemia is rare, ${ }^{3}$ and in the absence of headaches or other focal neurological findings, he did not undergo further analysis of his cerebrospinal fluid. The patient's white blood cell count was noted to be $265.7 \times 10^{9} / \mathrm{L}$ (reference range 4,500-10,000 $\times 10^{9} / \mathrm{L}$ ) with a hemoglobin of $7.8 \mathrm{~g} / \mathrm{dL}$ (reference range 13.3-17.2 $\mathrm{g} / \mathrm{dL}$ ) and platelets of $199 \times 10^{9} / \mathrm{L}$ (reference range $179 \times 10^{9} / \mathrm{L}-373 \times 10^{9} / \mathrm{L}$ ). Differential revealed $31 \%$ neutrophils, $5 \%$ bands, $48 \%$ myelocytes, $2 \%$ metamyelocytes, $1 \%$ basophils, $1 \%$ eosinophils, $2 \%$ monocytes, $4 \%$ promyelocytes, and $5 \%$ blasts.

One month into his induction therapy with imatinib (Gleevec $^{\circledR}$; Novartis International AG., Basel, Switzerland) 400 mg daily, he developed lower extremity edema and failed to show response to therapy; his white blood cell count remained elevated at $395.3 \times 10^{9} / \mathrm{L}$. His oncologist subsequently initiated therapy with omacetaxine (Synribo ${ }^{\circledR}$; Teva Pharmaceutical Industries., Petah Tikva, Israel) and demonstrated a rapid and effective hematologic response. As his white blood cell decreased, he was noted to have improved vision at subsequent ophthalmologic visits. His dilated fundus examinations demonstrated a gradual regression of his leukemic lesions at his 2 and 3 month follow up visits (Figure 1B and Figure 1C respectively). At 12 months from his initial presentation, there was complete resolution of his bilateral foveal infiltration, cotton-wool spots, and retinal hemorrhages (Figure 1D). OCT scans revealed restored foveal contour with focal defects at the photoreceptor outer segments (Figure 2C). By this point, the patient had successfully completed his induction therapy and was undergoing maintenance therapy. His best corrected visual acuity was 20/30 OU. The Virginia Commonwealth University (VCU) Institutional Review Board (IRB) does not

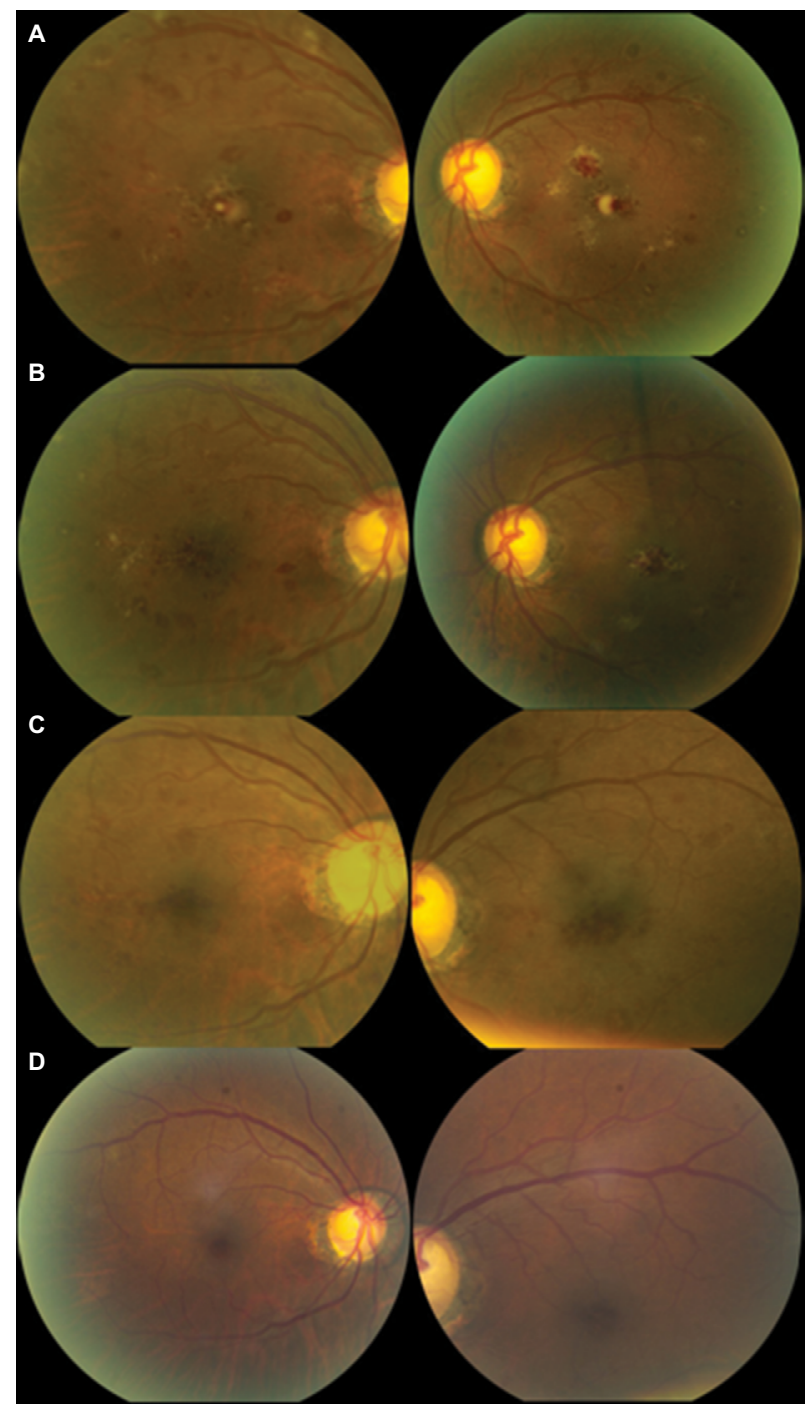

Figure I Interval fundus photography.

Notes: Color fundus photographs at presentation (A), 2 months (B), 3 months (C), and 12 months (D). At month 3, there is no clinical evidence of leukemic infiltration in the right eye (hemorrhages only) with a small residual area remaining just below the foveal center in the left. All lesions and intraretinal hemorrhages in the macula resolved by month 12 .

require approval for this case report as it does not constitute a human research subject that involves an investigational article. Written patient consent was obtained in compliance with VCU Health System, to use ophthalmic imaging and data in the publication of this case report.

\section{Comment}

Regardless of the type of leukemia, ocular manifestations can be found in up to half of the cases. ${ }^{1}$ Most of these manifestations, such as retinal hemorrhages, represent conditions associated with leukemia as opposed to direct leukemic infiltration. A prior report has demonstrated the time domain OCT findings of leukemic infiltration of the choroid with overlying serous detachment of the neurosensory retina, 


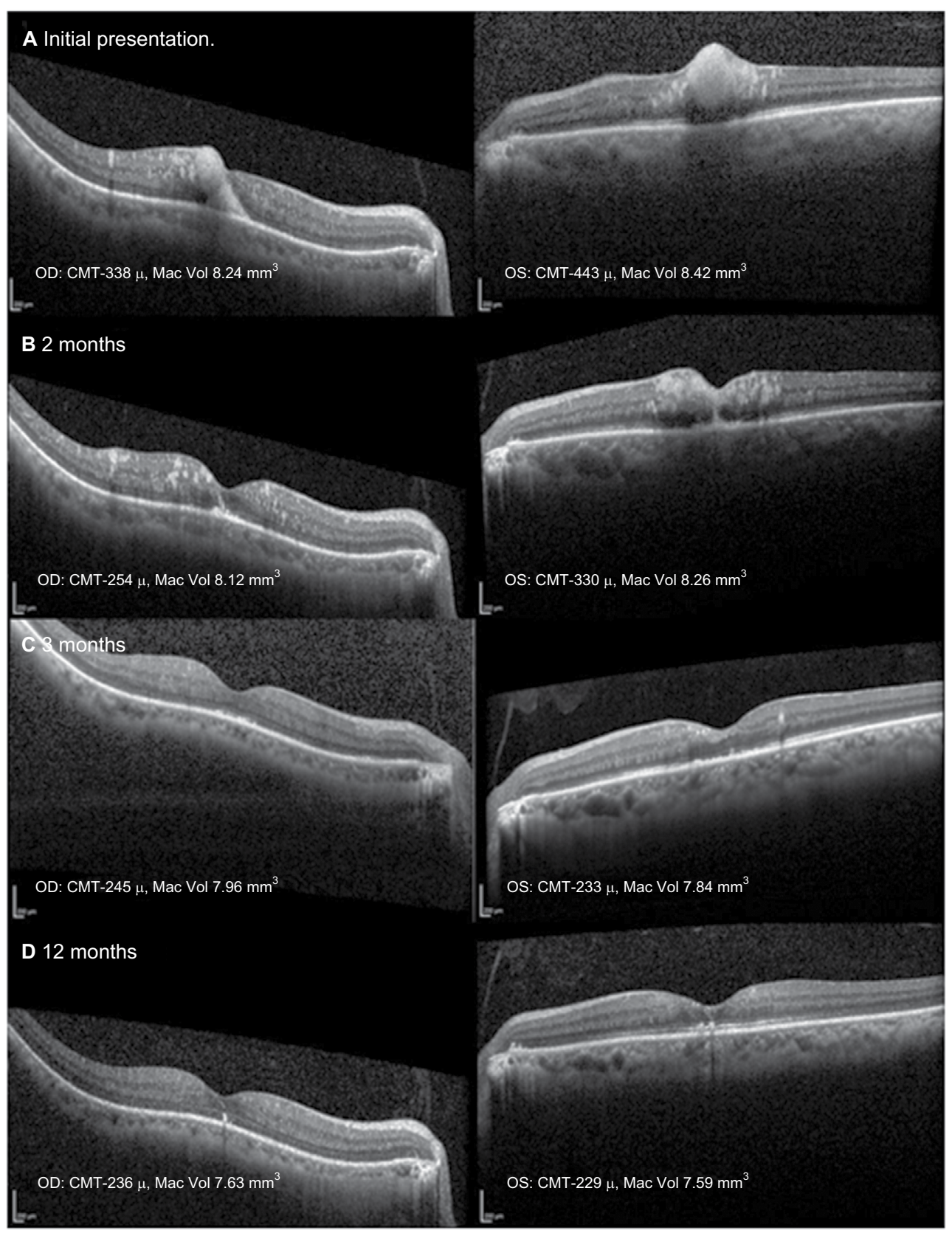

Figure 2 Serial spectral domain OCT images, with image registration, through the fovea at presentation (A), 2 months (B), 3 months (C), and I2 months (D).

Notes: (A) Initially, there were large inner foveal hyperreflective lesions in both eyes with a second outer retinal lesion in the right. (B) At 2 months, there were numerous smaller foci in the inner retina present after the larger lesion regressed in both eyes. There was a new area of outer retinal involvement in the left fovea. (C) There is complete resolution of the leukemic infiltrates in the right eye with minimal inner retinal involvement at the fovea in the left. (D) At I 2 months, there was complete restoration of the foveal contour with focal residual disruption of the photoreceptor outer segments in each eye.

Abbreviations: CMT, central macular thickness; Mac Vol, macular volume; OCT, optical coherence tomography; OD, oculus dexter; OS, oculus sinister.

which resolved following successful treatment. ${ }^{4}$ Further in another report, spectral domain OCT revealed the presence of choroidal thickening in addition to associated serous retinal detachment in a patient with recurrent leukemia. ${ }^{5}$

Our case is the first to demonstrate leukemic infiltration of the retina using OCT. It describes not only resolution of retinal hemorrhages associated with leukemia but also resolution of leukemic infiltration of the macula as well, following successful systemic treatment. Leukemic infiltration, as demon- strated in our scans, represents lesions of uniform reflectivity and can involve all layers of the retina. At month 3, there are persistent hemorrhages present in the foveal regions in both eyes (Figure 1C), with complete resolution of the infiltrates and the corresponding hyperreflective lesions on OCT on the right (Figure 2C). This indicates that the leukemic lesions are distinct entities from retinal hemorrhages on OCT. Finally, there was no consecutive atrophy of the inner retinal layers upon resolution, but there were focal disruptions of the photoreceptor 


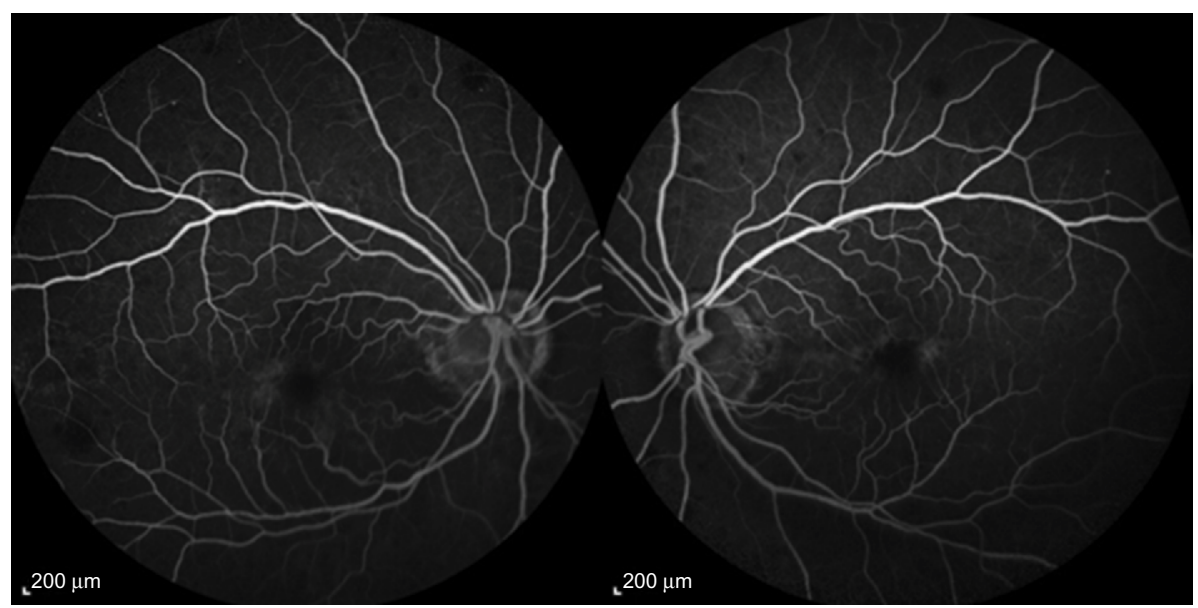

Figure 3 Intravenous fluorescein angiography at month 3.

Notes: There is no evidence of retinal vascular occlusion with minimal late perifoveal leakage. The foveal avascular zone and perifoveal capillary network are preserved. Images were obtained using a 55 degree objective.

outer segments where there was initial leukemic involvement. This was supported by fluorescein angiography, which was performed at 3 months from presentation, where there was preservation of the perifoveal capillary bed (Figure 3).

This report demonstrates a rare case of leukemic infiltration of the macula, documented with serial OCTs. Infiltration of the retina can be identified and monitored using OCT and should be employed in cases of suspected leukemic retinopathy.

\section{Disclosure}

The authors report no conflicts of interest in this work.

\section{References}

1. Schachat AP, Andrew PS, Jan A. Markowitz, JA. Graham. Ophthalmic manifestations of leukemia. Arch Ophthalmol. 1989;107(5): 697-700.

2. Carraro MC, Rossetti L, Gerli GC. Prevalence of retinopathy in patients with anemia or thrombocytopenia. Eur J Haematol. 2001;67(4): 238-244.

3. Lindhorst SM, Lopez RD, Sanders RD. An unusual presentation of chronic myelogenous leukemia: a review of isolated central nervous system relapse. J Natl Compr Canc Netw. 2013;11(7):745-750.

4. Candoni A,Simeone E,Bandello F,Fanin R. Leukaemic infiltration of the retina at onset of Philadelphia-positive acute lymphoblastic leukaemia revealed by stratus optical coherence tomography. $\mathrm{Br} J$ Haematol. 2006;133(5):45.

5. Chalam K, Patel CJ, Edwards J, Murthy RK. T-cell leukemia. Ophthalmology. 2012;119(8):1713-1714.e1.
International Medical Case Reports Journal

\section{Publish your work in this journal}

The International Medical Case Reports Journal is an international, peer-reviewed open-access journal publishing original case reports from all medical specialties. Previously unpublished medical posters are also accepted relating to any area of clinical or preclinical science. Submissions should not normally exceed 2,000 words or

\section{Dovepress}

4 published pages including figures, diagrams and references. The manuscript management system is completely online and includes a very quick and fair peer-review system, which is all easy to use. Visit http://www.dovepress.com/testimonials.php to read real quotes from published authors. 